\title{
Risks of Climate Change at Coastal Tourism in Bangladesh: A Study on Cox's Bazar
}

\author{
Sohel Ahmed, S. M \\ Department of Marketing, Lalmatia Mohila College, Bangladesh \\ smsohelahmed@gmail.com
}

\begin{abstract}
This study is on 'Risk of climate change at coastal tourism in Bangladesh. The main aim of this research is to describe the risks associated with climate change that has an impact on tourism. The study uses primary data collected from the respondents (Domestic, Local and International Tourists) by using various methods like; observation, survey and questionnaire. This research mainly adopts with close-ended questionnaire. This study uses Five Point Likert scale to measure the intensity of risk. This research identifies various types of risk like Rise of sea level, Rise of temperature, Acidic Sea, Damage Property, Damage infrastructure, Damage Livelihood, Damage environmental resources, Inundation during Storm, Risky Road, Heat Waves, Coastal Floods, Droughts, Pollution, Leads Powerful Hurricanes, and Allergy. This study also explores some other risks including Rainstorm, Disrupt Food Supply, Mangrove Deforestation, Saline Intrusion, Scarcity of Fresh Water, Population Displacement, Water Intrusion, Undermining of Local Communities, Coastline Erosion, Fish Stocks Inundate, Rough weather, Hot Sunshine with their intensity.
\end{abstract}

Keywords: Acidic, Climate, Coastal, Drought, Pollution,

\section{Introduction}

Government of Bangladesh is going to establish an exclusive tourist zone on 1100 acres of land near Cox's Bazar. This zone is only for exclusive foreign tourists (https://www.eturbonews.com). United Nations World Tourism Organization Tourism 2020 Vision forecasts that international arrivals will be nearly 1.6 billion by the year 2020 (https://www.ukessays.com). Oceans and seas play a crucial role in developing transport and tourism activities and a rise in sea level and sea temperatures, as well as more acidic oceans, would threaten infrastructure and erode natural attractions (https://climate.copernicus.eu).

Figure 1

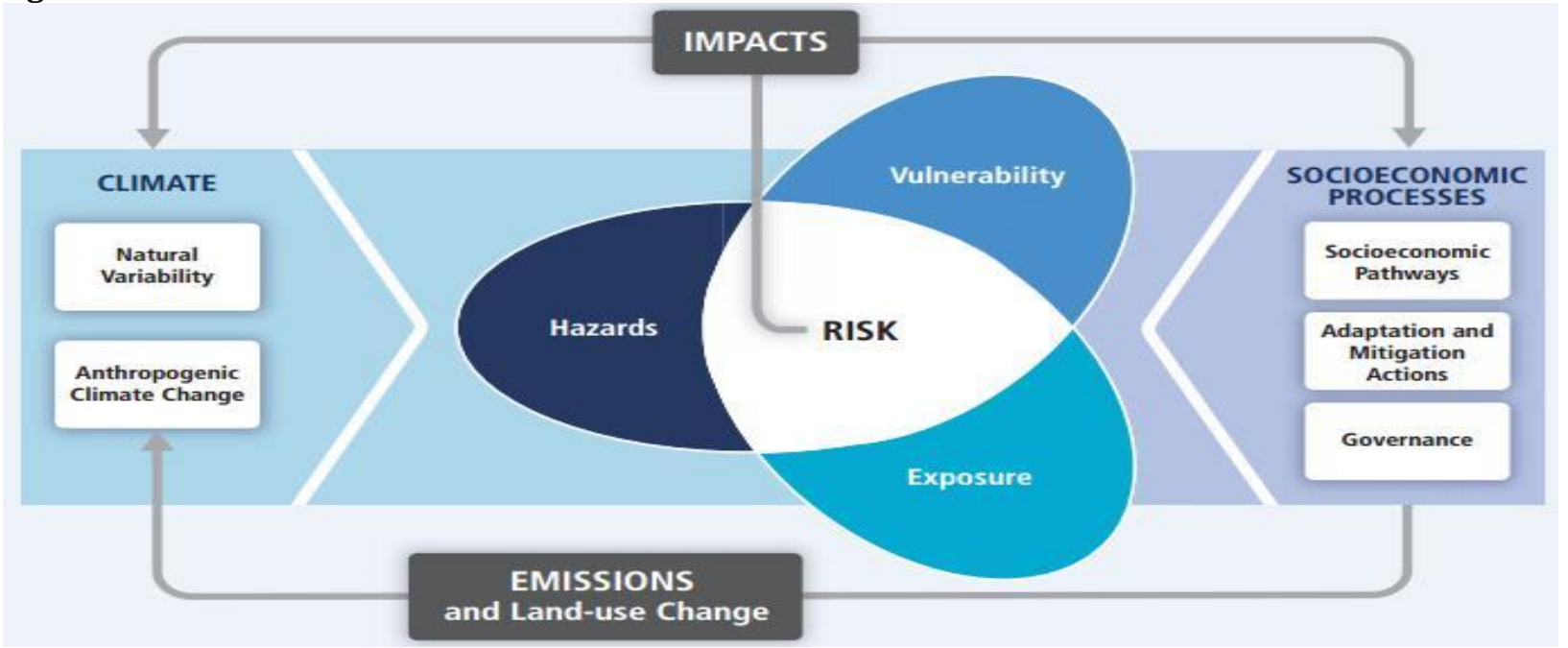

Source: https://coastadapt.com.au

Hazard refers to any potential occurrence of a natural or hsq4uman-induced physical event that may cause damage to property, infrastructure, livelihoods, service provision, environmental resources etc. Risk is the potential for consequence where something of value is at stake and where the outcome is uncertain, recognizing the diversity of values. Vulnerability encompasses a variety of concepts and elements including sensitivity or susceptibility to harm and lack of capacity to cope and adapt. Exposure refers to the degree to which a system exposes to a given hazard (e.g. sea-level rise). As an example, a coastal community in low- 
lying area can exposes to the certain degree of hazard of inundation during storm. Sensitivity refers to the degree to which a system is affected by, or responsive to hazard.

In other words, sensitivity captures the potential of a system. Hazard has direct impact on sensitivity. Criticality of the service determines sensitivity, (IPCC2014). Climate Change will increase the frequencies of extreme weather events such as floods, droughts, and heat waves in near future (https://ec.europa.eu). Global warming is now accelerating the rate of sea level rise (https://www.ucsusa.org). Climate change has significant implications for human health. Rising temperatures will likely lead to increased air pollution (https://www.ucsusa.org). Rising seas threaten to inundate low-lying areas and islands, damage property, and destroy ecosystems such as mangroves and wetlands that protect coasts against storms (https://www.nature.org). Sea level rise associated with climate change could displace tens of millions of people in low-lying areas - especially in developing countries (https://www.sciencedirect.com). The ocean is almost 40 percent more acidic than previous (https://www.sciencedirect.com). Smoke from wildfires degrades the air (https://www.sciencedirect.com). There have been large inter annual and inter decadal seasurface temperature changes off the West Coast of North America during the past 80 years (McGrown, 1998). Climate change will affect the health of urban populations (Kovats \& Akhtar, 2008).

The incidence of infection is sensitive to climate changes in areas of Southeast Asia, South America, and parts of Africa (Niessen \& Martens, 1995). The reduced rainfall in southeast Australia has placed this region's urban and rural communities on escalating water restrictions, with anthropogenic climate change forecasts suggesting that this drying trend will continue (Beebe \& Robert, 2009). Smallholder farmers faced frequent risks to their agriculture, including disease outbreaks, pest damage, and crop loss during storage and occurrence of extreme weather events (Harvey \& Rakotobe, 2014). Radioactive effects of anthropogenic changes in atmospheric composition cause climate changes, in particular an intensification of the global water cycle with a consequent increase in flood risk (Milly \& Wetherald, 2002). One of the major consequences of human-induced climate change and global warming is a greater occurrence of extreme weather events with potentially catastrophic effects for organizations, industries, and society (Linnenluecke \& Andrew, 2010). Climate change over the past 30 years has produced numerous shifts in the distributions and abundances of species (McGowan \& Cayan, 1980).

Research Gap: Change of climate that creates problems in selecting tourist destination. Tourists expect various types of facilities to select the destination. Tourism generates high level of employment, foreign direct investment, and foreign exchange for the borrowing countries. It is very effective tool for promoting sustainable development and poverty reduction. From this study, this country will be capable to identify the risk of climate change at costal tourism. Then Bangladesh will be able to minimize possible risk that will ensure quality service to tourists. Therefore, this research is important to students, researchers, and policy maker for social and economic development of Bangladesh.

Problem Statement: This study levels to find out the risk of climate change at coastal tourism in Bangladesh. Here, the consideration is on the "Risk of climate change at coastal tourism in Bangladesh perceived by respondents (Local, Domestic and International Tourists)". What are the risks of climate change creates problems in selecting tourist destination?

\section{Broad Objective of the Study}

Change of climate and risk of costal tourism in Bangladesh. Specific objectives are-

- To observe respondents' demographic profile,

- To observe individual tourist opinion towards risk of climate change,

- To make suggestions on the basis of findings,

\section{Methodology of the Research}

Type of Research: Type of this research is descriptive. This study is descriptive because it describes the characteristics of population in terms of factors that influence tourists' opinion mainly. A descriptive study is appropriate because it provides an accurate statement of the features of behavior, opinions, abilities, beliefs, 
and knowledge of a particular individual, situation, or group. The sea temperature is raising, maximum respondents awarded about the rise of sea temperature.

Sources of Data: This study uses both primary and secondary data. Various types of tourists (Local, Domestic and International) are appropriate to collect primary data. This study utilizes various types of sources to collect secondary data like, websites, trade journal, articles, newspaper, magazine, internet, periodicals, books, reports, and publications of associations related to tourism and change of climate, which are relevant to subject matter.

Instruments: The research put the relevant data in the MS word, Excel extracted from the respondents for frequency distribution. The researcher then analyze the data using the statistical software namely Statistical Package for Social Science (SPSS).

Measurement and Scaling Technique: This study uses different types of scale to collect the descriptive data like; nominal, interval, and ratio scale. The Likert scale is appropriate because it saves time, and easy to answer.

Questionnaire Design and Pretesting: This research mainly adopts with close-ended questionnaire. This study uses all the three methods of pretesting, the questionnaire to minimize any error or bias namely planned field survey, personal interviews (face to face), and expert panel.

\section{Sampling Design}

Populations: Population of the study consists of current individual tourist, group tourist, local, domestic, and foreign tourists. Population of the study consists of elements and unit. Elements are all tourists in Coxes Bazar. Unit is each individual tourist. Elements are male and female. Sampling unit is each individual tourist.

Extent: The research extent is Costal area in Coxes Bazar.

Sampling Frame: Sampling frame includes gathering places of tourists.

Sampling Technique: Cluster sampling method is appropriate for the study. Each cluster contains various types of characteristics. This study uses multi stage sampling design. The first stage will cover geographic areas. Second stage will cover few tourist places and final stage will cover educational levels of the respondents.

Sample Size: This study uses convenience sample size.

Fieldwork or Data Collection: This research will ensure voluntary (not forced) participation of the respondents; assure the confidentiality and security of the respondent's personal and private information; will ensure honesty, transparency, and objectivity, without intruding. Harming, or adversely affecting the respondents; will not 1) sell and not influence opinions of the respondents, 2) mislead or pressurize a respondent when asking them to take part, 3) eat or smoke in front of the respondents, 4) make any comments on the respondent's answer and offer any comments or opinion of his own.

Data Preparation and Data Analysis: This is appropriate with quantitative analysis. As a part of quantitative analysis the popular statistical tools such as frequency distribution is accurate to reach to the objectives.

Reliability and Validity: This study ensures reliability by 1) adopting the findings of the previous studies to construct the questionnaire items and by 2) pretesting, the questionnaire, removing confusing words, and improving their clarity of the questions items, free from collector bias. This study ensures validity by confirming all the respondents are representative to provide the data. Researcher personally distributed all questions among subjects. 
Statistical Analysis: For the present study, frequency distribution is applicable to explain the data. The nature of the research is quantitative. This study uses both primary and secondary data. Various types of methods like observation, survey, and questionnaire are accurate to collect primary data.

\section{Results and Discussion}

Total respondents were 45 for this study. The majority of the respondents were in 25-34 years old. Eightyseven percent respondents were young, aged were 25-34 years, seven percent of the respondents were below 25 years old. Four percent of the respondents were 35-44 years old. Only two percent respondents were 4560 years old. None of the respondents was over 60 years old. The highest numbers of respondents were male. Fifty-three percent respondents were male and forty-seven percent respondents were female. The ratio of the respondents is same.

Education: The educational status of the selected respondents in terms of percentage of literacy varying level was four percent had secondary (SSC) level education, seven percent had higher secondary (HSC) level education, seventy-one percent had graduation level education, and eighteen percent who had postgraduation level education. None of the respondents was illiterate. The highest numbers of respondents were graduates. That means educated people use these recreational services.

Income: The monthly income (Taka) status of the selected respondents in terms of percentage of income varying level was seven percent had less than 10,000, twenty percent had 10000-20000, thirty-eight percent had 20000-30000, 26.67\% who had 30000-50000, two percent had 50000-80000, and seven percent had above 80000 .

Occupation: The most of the respondents were students. Seventy-three percent respondents were students, sixteen percent were service holder, nine percent were from business, and two percent respondents were homemaker.

Religion: Hundred percent respondents were Muslim. None of the respondents was other religion.

\section{Descriptive Statistics (Risk of Climate Change)}

\begin{tabular}{llll}
\hline & N & Mean & Std. Deviation \\
\hline Sea level rises due to climate change & 45 & 3.5333 & 1.03573 \\
Sea temperature rises & 45 & 3.3111 & 1.01852 \\
Sea is acidic & 45 & 3.4444 & 1.42311 \\
Risk of climate change is to damage property & 45 & 3.7111 & 1.10005 \\
It damages infrastructure & 45 & 3.2222 & 1.25931 \\
It damages livelihood & 45 & 3.4667 & 1.15994 \\
It damages environmental resources & 45 & 3.5556 & 1.13929 \\
Inundation during storm & 45 & 3.8000 & .91949 \\
Road falls in risk & 45 & 3.8222 & 1.13396 \\
It causes heat waves & 45 & 3.3333 & 1.08711 \\
Coastal flood increases & 45 & 3.6222 & 1.05073 \\
Drought increases & 45 & 2.8000 & 1.17937 \\
Pollution increases & 45 & 3.8889 & 1.04929 \\
Precipitation increases & 45 & 3.4444 & 1.13929 \\
It lead powerful hurricane & 45 & 2.6667 & 1.14812 \\
People suffer from allergy & 45 & 2.9111 & 1.18364 \\
It causes rainstorm & 45 & 3.5556 & 1.01255 \\
It disrupts food supply & 45 & 3.2667 & 1.07450 \\
Mangrove deforestation & 45 & 3.4667 & 1.35848 \\
Saline intrusion & 45 & 3.6444 & 1.29957 \\
Coastal acquiescent & 45 & 3.1333 & 1.12006 \\
Scarcity of fresh water & 45 & 3.7333 & .93905 \\
\hline
\end{tabular}




\begin{tabular}{llll}
\hline Population displacement & 45 & 3.5556 & 1.09867 \\
\hline Subsistence of local communities & 45 & 3.2667 & 1.15601 \\
Coastline erosion & 45 & 3.5111 & .89499 \\
Water intrusion & 45 & 3.7556 & 1.02593 \\
It reduces fish stocks & 45 & 3.3111 & 1.14460 \\
Inundate low-lying areas & 45 & 3.7333 & 1.17551 \\
Rough Weather & 45 & 3.2444 & 1.13128 \\
Hot sunshine & 45 & 3.8667 & .89443 \\
Salt water intrusion & 45 & 3.3556 & 1.17077 \\
Valid N (list wise) & 45 & & \\
\hline
\end{tabular}

The distribution of sea level is rising due to climate change is normal with mean 3.533 and standard deviation 1.04. The distribution of sea temperature rises is normal with mean 3.311 and standard deviation 1.02 . The distribution of sea is acidic is normal with mean 3.444 and standard deviation 1.42. The distribution of risk of climate change is to damage property is normal with mean 3.711 and standard deviation 1.10. The distribution of it damages infrastructure is normal with mean 3.222 and standard deviation 1.26. The distribution of it damages livelihood is normal with mean 3.467 and standard deviation 1.16. The distribution of it damages environmental resources is normal with mean 3.566 and standard deviation 1.14. The distribution of inundation during storm is normal with mean 3.800 and standard deviation 0.92 . The distribution of road falls in risk is normal with mean 3.822 and standard deviation 1.13. The distribution of it causes heat waves is normal with mean 3.333 and standard deviation 1.09. The distribution of coastal flood increases is normal with mean 3.622 and standard deviation 1.05. The distribution of drought increases is normal with mean 2.800 and standard deviation 1.18. The distribution of pollution increases is normal with 3.889 and standard deviation 1.05. The distribution of Precipitation increases is normal with mean 3.444 and standard deviation 1.14 .

The distribution of it leads powerful hurricanes is normal with mean 2.667 and standard deviation 1.15. The distribution of people suffer from allergy is normal with mean 2.911 and standard deviation 1.18. The distribution of it causes rain storm is normal with mean 3.556 and standard deviation 1.01. The distribution of it disrupt food supply is normal with mean 3.267 and standard deviation 1.07. The distribution of mangrove deforestation is normal with mean 3.467 and standard deviation 1.36. The distribution of saline intrusion is normal with mean 3.644 and standard deviation 1.30. The distribution of coastal acquiescent is normal with mean 3.133 and standard deviation 1.12. The distribution of scarcity of fresh water is normal with mean 3.733 and standard deviation 0.94 . The distribution of population displacement is normal with mean 3.556 and standard deviation 1.10. The distribution of subsistence of local communities is normal with mean 3.267 and standard deviation 1.16. The distribution of coastline erosion is normal with mean 3.511 and standard deviation 0.89 . The distribution of water intrusion is normal with mean 3.756 and standard deviation 1.03. The distribution of it reduces fish stocks is normal with mean 3.311 and standard deviation 1.14. The distribution of inundating low-lying area is normal with mean 3.733 and standard deviation 1.18. The distribution of rough weather is normal with mean 3.244 and standard deviation 1.13.

The distribution of hot sunshine is normal with mean 3.867 and standard deviation 0.89 . The distribution of salt water is normal with mean 3.356 and standard deviation 1.17. The sea level raises, the most of the respondents concerned about the rise of sea level. Thirty-eight percent respondents somehow agreed that the sea level has been rising. Twenty percent respondents strongly agreed with the portrayal, twenty-seven percent agreed with the description, thirteen percent respondents disagreed with the affirmation. Only two percent respondents strongly disagreed with the announcement. Total $85 \%$ respondents agreed that the sea level rise than previous. Global warming is now accelerating the rate of sea level rise (https://www.ucsusa.org). Thirty-three percent respondents somehow agreed that the sea temperature is rising; twenty-nine percent agreed with the description, eleven percent strongly agreed with the narration. Twenty-two percent respondents disagreed with the portrayal; four percent respondents strongly disagreed with the representation. Total seventy-three percent respondents agreed that the sea temperature has been rising. Oceans and seas play a crucial role in developing transport and tourism activities and a rise in sea level 
and sea temperatures (https://climate.copernicus.eu). The sea is acidic; sixty-seven percent respondents agreed that the sea is acidic.

The highest numbers of respondents do strongly agreed that the sea is acidic (27\%); twenty-four percent agreed with the description, sixteen percent respondents somehow agreed with the portrayal. Twenty percent respondents disagreed with the story; thirteen percent respondents strongly disagreed with the description. The ocean is almost 40 percent more acidic than previous (https://www.sciencedirect.com). It damages property, the most of the respondents agreed that the result of climate change is to damage property (80\%), thirty-one percent respondents agreed with the portrayal; twenty-seven percent respondents strongly agreed with the announcement, twenty-two percent respondents somehow agreed with the description. twenty respondents disagreed with the story. Seas play a crucial role in developing transport and tourism activities and a rise in sea level and sea temperatures, as well as more acidic oceans, would threaten infrastructure and erode natural attractions and damage property (https://climate.copernicus.eu). It Damages infrastructure, sixty-two percent respondents agreed that the result of climate change is to damage infrastructure. Twenty percent respondents strongly agreed with the portrayal, thirty-one respondents agreed with the story, eleven percent respondents somehow agreed with the description. Thirtyone percent respondents disagreed with the argument; seven percent respondents strongly disagreed with the description. Hot weather, flooding, and other extreme weather events damage infrastructure (https://www.edf.org). It Damages Livelihood, seventy-one percent respondents agreed that it causes the damage of livelihood.

Twenty-two percent respondents strongly agreed with the portrayal, twenty percent respondents agreed with the story, and twenty-nine percent respondents somehow agreed with the description. Twenty-seven percent respondents disagreed with the story; two percent respondents strongly disagreed with the story. It damages environmental resources; eighty-two percent respondents agreed that climate change causes the damage of environmental resources. Twenty-seven percent respondents strongly agreed with the portrayal, thirty-one percent respondents agreed with the description, twenty-four percent respondents somehow agreed with the story. Sixteen percent respondents disagreed with the description; two percent respondents strongly disagreed with the portrayal. Inundation during storm: eighty-nine percent respondents agreed with the story. Twenty-four percent respondents strongly agreed with the description, thirty-six percent respondents agreed with the portrayal, twenty-nine percent respondents somehow agreed with the story. Eleven percent respondents disagreed with the portrayal, none of the respondents strongly disagreed with the story. Rising seas threaten to inundate low-lying areas (https://www.nature.org). Road falls in risk: 86\% respondents agreed with the statement. Thirty-three percent respondents strongly agreed with the portrayal, thirty-one percent respondents agreed with the statement, twenty-two percent respondents somehow agreed with the story. Four percent respondents disagreed with the statement; two percent respondents strongly disagreed with the description. Hot weather, flooding damage infrastructure, put heavy burdens on electrical supplies and disrupt how people travel and communicate (https://www.edf.org).

Heat Waves: Seventy-four percent respondents agreed with the portrayal. Eleven percent respondents strongly agreed with the story, thirty-six percent respondents agreed with the story, twenty-seven percent respondents somehow agreed with the description. Fifteen percent respondents disagreed with the story; eleven percent respondents strongly disagreed with the portrayal. Extreme summer heat means more deaths during heat waves (https://www.sciencedirect.com). Heat is one of the top weather-related causes of death in the US, with an average of more than 600 deaths per year (https://blog.ucsusa.org).

Coastal Flood: Eighty-nine percent respondents agreed with the statement. Eighteen percent respondents strongly agreed with the statement, thirty-three respondents agreed with the statement, thirty-eight percent respondents somehow agreed with the statement. Four percent respondents disagreed with the statement; seven percent respondents strongly disagreed with the statement. Flooding damages infrastructure (https://www.edf.org).

Droughts: Thirty-nine percent respondents agreed with the statement. Four percent respondents strongly agreed with the statement, eighteen percent respondents agreed with the statement, twenty-seven percent respondents somehow agreed with the statement. Forty percent respondents disagreed with the statement; 
eleven percent respondents strongly disagreed with the statement. Climate Change will increase the frequencies of extreme weather events such as droughts, and heat waves in near future (https://ec.europa.eu).

Air Pollution: Eighty-seven percent respondents agreed with the portrayal. Thirty-eight percent respondents strongly agreed with the description, thirty-one percent respondents agreed with the story, eighteen percent respondents somehow agreed with the description. Forty percent respondents disagreed with the portrayal; eleven percent respondents strongly disagreed with the story. It shows that climate change causes air pollution. Rising temperatures will likely lead to increased air pollution (https://www.ucsusa.org).

Precipitation: Eighty-two percent respondents agreed with the portrayal. Eighteen percent respondents strongly agreed with the description, thirty-six percent respondents agreed with the story, twenty-nine percent respondents somehow agreed with the affirmation. Seventeenth percent respondents disagreed with the description, none of the respondents strongly disagreed with the statement. August 2018 saw very dry conditions, indicated by much below average precipitation, relative humidity and soil moisture compared to the 1981-2010 average in large regions to the north and east of the Black Sea and to the south and east of the Caspian Sea, in northeastern Siberia, central and eastern Mexico (https://climate.copernicus.eu).

Hurricanes: Ninety-one percent respondents agreed with the description. Eighteen percent respondents strongly agreed with the narration, twenty-nine percent respondents agreed with the story, forty-two percent respondents somehow agreed with the portrayal. Four percent respondents disagreed with the story; seven percent respondents strongly disagreed with the description. The increased evaporation of water is like fuel for storms, exacerbating extreme weather events, such as hurricanes (https://www.sciencedirect.com). People have been suffering from allergy, fifty-three percent respondents agreed with the narration. Two percent respondents strongly agreed with the account, twenty-nine percent respondents agreed with the assertion, twenty-two percent respondents somehow agreed with the narration. Thirty-four percent respondents disagreed with the description; thirteen percent respondents strongly disagreed with the story. Rising temperatures will likely lead to increased air pollution, a longer and more intense allergy, heavier rainstorms and flooding. All of these changes pose serious, and costly, risks to public health (https://www.ucsusa.org). Insect borne diseases are increasing, eighty percent respondents agreed with the story. Twenty percent respondents strongly agreed with the narration, thirty-six percent respondents agreed with the story, twenty-four percent respondents somehow agreed with the portrayal. Eighteen percent respondents disagreed with the narration, $0 \%$ respondents strongly disagreed with the representation. Rising temperatures will likely the spread of insect-borne diseases (https://www.ucsusa.org).

Heavy Rainstorm: Eighty percent respondents agreed with the statement. Twenty percent respondents strongly agreed with the portrayal, thirty-six percent respondents agreed with the description, twenty-four percent respondents somehow agreed with the story. Thirteen percent respondents disagreed with the statement; seven percent respondents strongly disagreed with the description. It disrupts our food supply seventy-three percent respondents agreed with the story. Twenty-nine percent respondents strongly agreed with the portrayal, twenty-nine percent respondents agreed with the story, fifteen percent respondents somehow agreed with the portrayal. Fifteen percent respondents disagreed with the story; twelve respondents strongly disagreed with the description. It causes our mangrove deforestation seventy-six percent respondents agreed with the portrayal. Twenty-seven percent respondents strongly agreed with the story, forty percent respondents agreed with the description, nine percent respondents somehow agreed with the story. Twelve percent respondents disagreed with the story; twelve respondents strongly disagreed with the portrayal.

As deforestation increases, people may find that some groups of golden-headed lion tamarind monkeys, separated into tree 'islands', adapt better to climate change than others (https://www.sciencedirect.com). It causes saline intrusion, seventy-four percent respondents agreed with the portrayal. Eleven percent respondents strongly agreed with the story, sixteen percent respondents agreed with the description, fortyseven percent respondents somehow agreed with the portrayal. Four respondents disagreed with the story; seven respondents strongly disagreed with the portrayal. It causes coastal acquiescent, eighty percent respondents agreed with the story. Sixteen percent respondents strongly agreed with the fact, forty-four 
percent respondents agreed with the description, twenty percent respondents somehow agreed with the portrayal. Eighteen percent respondents disagreed with the story; two percent respondents strongly disagreed with the story. It creates problem on fresh water resources, ninety-one percent respondents agreed with the fact.

Twenty-six percent respondents strongly agreed with the story, twenty-nine percent respondents agreed with, the portrayal, thirty-six percent respondents somehow agreed with the description. Seven percent respondents disagreed with the story; two percent respondents strongly disagreed with the description. It causes population displacement, eighty percent respondents agreed with the story. Fifteen percent respondents strongly agreed with the statement, forty-five percent respondents agreed with the fact. Twenty percent respondents somehow agreed with the description. Eighteen percent respondents disagreed with the story; two percent respondents strongly disagreed with the description. Recreation and tourism industries are weather-dependent - with many planning based on historic weather patterns, which climate change will disrupt. As we move into an era in which climate change impacts are all around the people, adapting to these changes quickly will be a key for all sectors of the global economy (https://www.sciencedirect.com). It causes undermining subsistence of local communities, ninety-one percent respondents agreed with the description. Twenty-six percent respondents strongly agreed with the narration, twenty-nine percent respondents agreed with the representation, thirty-six percent respondents somehow agreed with the account. Seven percent respondents disagreed with the story; two percent respondents strongly disagreed with the explanation. It causes coastline erosion, seventy-six respondents agreed with the description. Nine percent respondents strongly agreed with the statement, thirty-one percent respondents agreed with the statement, thirty-six respondents somehow agreed with the statement. Twenty percent respondents disagreed with the narration; four percent respondents strongly disagreed with the story. It reduces fish stocks, eighty-seven percent respondents agreed with the narration.

Twenty-nine percent respondents strongly agreed with the description, forty-two percent respondents agreed with the story, sixteen percent respondents somehow agreed with the portrayal. Nine percent respondents disagreed with this argument; Four percent respondents strongly disagreed with the announcement. Warming seas has been reducing the fish stock (https://www.sciencedirect.com). It causes inundate low-lying areas, seventy-eight percent respondents agreed with this assertion. Sixteen percent respondents strongly agreed with the affirmation, twenty-nine percent respondents agreed with the narration, thirty-three percent respondents somehow agreed with the description. Thirteen percent respondents disagreed with the account; nine percent respondents strongly disagreed with the portrayal. Sea level rise associated with climate change could displace tens of millions of people in low-lying areas, especially in developing countries. It causes rough weather, eighty-nine percent respondents agreed with the narration. Eighteen percent respondents strongly agreed with the description, thirty-three respondents agreed with the assertion, thirty-eight percent respondents somehow agreed with the description. Eighteen percent respondents disagreed with the portrayal; four percent respondents strongly disagreed with the representation. It causes hot sunshine, ninety-four percent respondents agreed with the narration. Twentytwo percent respondents strongly agreed with the announcement, fifty-four respondents agreed with the description, eighteen percent respondents somehow agreed with the story. Four percent respondents disagreed with the description; two percent respondents strongly disagreed with the tracing. Duration of Sunshine in 2018 was exceptionally high across many parts of Europe. Some regions experienced 20\% more, including the Netherlands, Germany, Poland, Norway, Sweden, and mainland Britain.

\section{Conclusion}

Tourism contributes to economic development and social welfare. It offers unique attractions - including various culture, subculture, and natural places. Tourism industry contains various types of industries that contribute to national GDP-like photography, natural resources, leisure, and recreational industry. Each industry has unique contribution to economic growth. Therefore, tourism is important to each country. The marketers' task is to explore the needs/benefits of tourism and present it to tourist. Here, the marketers' challenge is to minimize negative impact. Policy maker should need to know about the risk of climate change and minimization procedures. This research identifies various types of risk like Rise of sea level, Rise of temperature, Acidic Sea, Damage Property, Damage infrastructure, Damage Livelihood, Damage 
environmental resources, Inundation during Storm, Risky Road, Heat Waves, Coastal Floods, Droughts, Pollution, Leads Powerful Hurricanes, and Allergy. This study also explores some other risks including Rainstorm, Disrupt Food Supply, Mangrove Deforestation, Saline Intrusion, Scarcity of Fresh Water, Population Displacement, Water Intrusion, Undermining of Local Communities, Coastline Erosion, Fish Stocks Inundate, Rough weather, Hot Sunshine with their intensity.

\section{Recommendations}

Tourism industry is one of the fastest growing sectors not only in Bangladesh but also in the whole world playing the crucial role in their economy. Like other countries these sector can prove as a key player in recreational sector. Though government of Bangladesh have already started their journey in this way, there needs a lot of changes and improvements to be a friendly actor. This study detects risks of climate change on costal tourism in Bangladesh, now this country will be able to minimize possible risk that will ensure quality service to tourists. Therefore, this research is important to students, researchers, and policy maker for social and economic development of Bangladesh. Some sorts of action are necessary to improve the present condition of climate change:

- To reduce the tree cutting at the coastal area,

- To avoid the waste dumping at the riverside of Bakkhali (Bangladesh),

- To remove the use of poly -ethylene materials like packet of chips,

- To remove plastic water bottle and others from the sea beach/costal reason, to monitor the water quality and reduce the pollution,

- To plan for trees/ forest keeping at the coastal region according to the percentage of forest required at the costal maintained and balancing environmental operation at this area,

- To save the wild animal and nature by stepping the policy/rule at the coastal region,

- To remove Roinga, who have come from Myanmar (They are polluting environment),

- To eliminate hill cutting,

- To increase awareness among people,

- To introduce proper waste management system,

- To reduce the uses of chemical at land,

- To improve tourism management system,

\section{References}

Beebe N., W., Robert, M., C., Pipi, D. \& Sweeney A., W. (2009). Australia's Dengue Risk Driven by Human Adaptation to Climate Change, PLOS Neglected Tropical Disease.

Harvey C., A., Rakotobe, H., Z., Lalaina, R. N., S., Radhika, R., Hery, R. R, Hasinandrianina, R., H. \& MacKinnon J., L. (2014). Extreme vulnerability of smallholder farmers to agricultural risks and climate change in Madagascar, the Royal Society Publishing.

Kovats, S. \& Akhtar, R. (2008). Climate, climate change and human health in Asian cities, SAGE journal, International Institute for Environment and Development, 20(1), 165-175.

Linnenluecke. \& Andrew, M. (2010). Beyond Adaptation: Resilience for Business in Light of Climate Change and Weather extremes, SAGE Journal, 49(3), 477-511.

McGowan, John A., Cayan, Daniel R. \& Dorman, LeRoy M. (1980). Climate-Ocean Variability and Ecosystem Response in the Northeast Pacific, Journal of Science, 281(5374), 210-217.

McGrown, J. A. \& Cayan D., R. (1998). Climate-Ocean Variability, and Ecosystem Response in the Northeast Pacific, Journal of Science, 281(5374), 210-217.

Milly, P. C. D., Wetherald, R. T., Dunne, K. A. \& Delworth, T. L. (2002). Increasing risk of great floods in a changing climate, Journal of Nature 415, 514-517.

Niessen, W. J., Martens, Niessen, L. W., Rotmans, Iette, J. \& McMichael, A. J. (1995). Potential impact of global climate change on malaria risk, Environmental Health Perspectives, 103(5), 457-464.

https://www.ipcc.ch (Accessed 13 June 2018)

https://www.ucsusa.org (Accessed 13 June 2018)

https://www.nature.org (Accessed 13 June 2018)

https://www.edf.org (Accessed 13 June 2018)) 
https://ec.europa.eu (Accessed 13 June 2018)

https://www.sciencedirect.com (Accessed14 June 2018)

https://climate.copernicus.eu (Accessed 14 June18)

https://climate.copernicus.eu (Accessed 14 June 18)

http://www.sl.undp.org (Accessed 14 June 2018)

https://climate.copernicus.eu (Accessed 19 July 2019)

https://blog.ucsusa.org (Accessed 20 July 2019)

(https://www.eturbonews.com (Accessed 13 June 2018)

\section{Appendix-1}

Table 1: Descriptive Statistics of the Selected Characteristics of the Interviewee

\begin{tabular}{|c|c|c|c|}
\hline Characteristics & Categories & Respondents & Percentage \\
\hline \multirow[t]{4}{*}{ Age } & Below 25 Years & 03 & $07 \%$ \\
\hline & 25-34 Years & 39 & $87 \%$ \\
\hline & $35-44$ years & 02 & $04 \%$ \\
\hline & $\begin{array}{l}45-60 \text { years } \\
\text { Over } 60 \text { years }\end{array}$ & $\begin{array}{l}01 \\
00\end{array}$ & $\begin{array}{l}02 \% \\
00 \%\end{array}$ \\
\hline \multirow[t]{2}{*}{ Gender } & Male & 24 & $53 \%$ \\
\hline & Female & 21 & $47 \%$ \\
\hline \multirow[t]{8}{*}{ Education } & $\mathrm{PhD}$ & 00 & $00 \%$ \\
\hline & Post Graduate & 08 & $18 \%$ \\
\hline & Graduation & 32 & $71 \%$ \\
\hline & HSC & 03 & $07 \%$ \\
\hline & SSC & 02 & $04 \%$ \\
\hline & Primary School & 00 & $00 \%$ \\
\hline & Literate & 00 & $00 \%$ \\
\hline & Others & 00 & $00 \%$ \\
\hline \multirow[t]{6}{*}{ Income } & Less Than 10000 & 03 & $07 \%$ \\
\hline & $! 0000-20000$ & 09 & $20 \%$ \\
\hline & $20000-30000$ & 17 & $38 \%$ \\
\hline & $30000-50000$ & 12 & $27 \%$ \\
\hline & $50000-80000$ & 01 & $02 \%$ \\
\hline & Above 80000 & 03 & $07 \%$ \\
\hline \multirow[t]{4}{*}{ Occupation } & Student & 33 & $73 \%$ \\
\hline & Service & 07 & $16 \%$ \\
\hline & Business & 04 & $09 \%$ \\
\hline & Others & 01(House Wife) & $02 \%$ \\
\hline \multirow[t]{3}{*}{ Religion } & Muslim & 45 & $100 \%$ \\
\hline & Hindu & 00 & $00 \%$ \\
\hline & Other & 00 & $00 \%$ \\
\hline
\end{tabular}

Source: Field Study 
Table 2: Responses Concerning Tourist Attitude towards Risks of Climate Change at Coastal Tourism in Bangladesh

The score for each statement could range from, 1 to 5 . For the positive/negative statement $\&$ here, $\mathbf{1}=$ Strongly Disagree, 2= Disagree, $\mathbf{3}=$ Somehow Agree, $\mathbf{4}=$ Agree, $\mathbf{5}=$ Strongly Agree

\begin{tabular}{|c|c|c|c|c|c|}
\hline Opinion About Risk of Climate Change & 1 & 2 & 3 & 4 & 5 \\
\hline \multirow{2}{*}{ 1. Do you think the sea level raise? } & 01 & 06 & 17 & 12 & 09 \\
\hline & $02 \%$ & $13 \%$ & $38 \%$ & $27 \%$ & $20 \%$ \\
\hline \multirow[t]{2}{*}{ 2. Do you think the sea temperature raise? } & 02 & 10 & 15 & 13 & 05 \\
\hline & $4 \%$ & $22 \%$ & $33 \%$ & $29 \%$ & $11 \%$ \\
\hline \multirow[t]{2}{*}{ 3. Do you think the sea is acidic? } & 06 & 07 & 09 & 11 & 12 \\
\hline & $13 \%$ & $20 \%$ & $16 \%$ & $24 \%$ & $27 \%$ \\
\hline \multirow[t]{2}{*}{ 4. Does it damage property? } & 00 & 09 & 10 & 14 & 12 \\
\hline & $00 \%$ & $20 \%$ & $22 \%$ & $31 \%$ & $27 \%$ \\
\hline \multirow{2}{*}{ 5. Does it damage infrastructure? } & 03 & 14 & 05 & 14 & 09 \\
\hline & $7 \%$ & $31 \%$ & $11 \%$ & $31 \%$ & $20 \%$ \\
\hline \multirow[t]{2}{*}{ 6. Does it damage livelihood? } & 01 & 12 & 13 & 09 & 10 \\
\hline & $02 \%$ & $27 \%$ & $29 \%$ & $20 \%$ & $22 \%$ \\
\hline \multirow[t]{2}{*}{ 7. Does it damage environmental resources? } & 01 & 07 & 11 & 14 & 12 \\
\hline & $02 \%$ & $16 \%$ & $24 \%$ & $31 \%$ & $27 \%$ \\
\hline \multirow[t]{2}{*}{ 8. Does the area become inundation during storm? } & 00 & 05 & 13 & 16 & 11 \\
\hline & $00 \%$ & $11 \%$ & $29 \%$ & $36 \%$ & $24 \%$ \\
\hline \multirow[t]{2}{*}{ 9. Does the road fall in risk? } & 02 & 04 & 10 & 14 & 15 \\
\hline & $5 \%$ & $9 \%$ & $22 \%$ & $31 \%$ & $33 \%$ \\
\hline \multirow[t]{2}{*}{ 10. What is the present condition of heat waves? } & 05 & 07 & 12 & 16 & 05 \\
\hline & $11 \%$ & $15 \%$ & $27 \%$ & $36 \%$ & $11 \%$ \\
\hline \multirow[t]{2}{*}{ 11. Do you think coastal flood increase? } & 03 & 02 & 17 & 15 & 08 \\
\hline & $07 \%$ & $04 \%$ & $38 \%$ & $33 \%$ & $18 \%$ \\
\hline \multirow{2}{*}{ 12. Do you think droughts have been increase? } & 05 & 18 & 12 & 08 & 02 \\
\hline & $11 \%$ & $40 \%$ & $27 \%$ & $18 \%$ & $04 \%$ \\
\hline \multirow[t]{2}{*}{ 13. Do you think air pollution increase? } & 01 & 05 & 08 & 14 & 17 \\
\hline & $02 \%$ & $11 \%$ & $18 \%$ & $31 \%$ & $38 \%$ \\
\hline \multirow[t]{2}{*}{ 14. Do you think precipitation increase? } & 00 & 08 & 16 & 13 & 08 \\
\hline & $00 \%$ & $18 \%$ & $36 \%$ & $29 \%$ & $17 \%$ \\
\hline \multirow[t]{2}{*}{ 15. Do you think it leads powerful hurricanes? } & 08 & 13 & 19 & 02 & 03 \\
\hline & $18 \%$ & $29 \%$ & $42 \%$ & $04 \%$ & $7 \%$ \\
\hline \multirow[t]{2}{*}{ 16. Do you think people have been suffering from allergy? } & 06 & 15 & 10 & 13 & 01 \\
\hline & $13 \%$ & $34 \%$ & $22 \%$ & $29 \%$ & $2 \%$ \\
\hline \multirow[t]{2}{*}{ 17. Do you think insect borne disease increase? } & 01 & 08 & 11 & 16 & 09 \\
\hline & $2 \%$ & $18 \%$ & $24 \%$ & $36 \%$ & $20 \%$ \\
\hline \multirow[t]{2}{*}{ 18. Are you observing heavy rainstorm? } & 03 & 06 & 11 & 16 & 09 \\
\hline & $07 \%$ & $13 \%$ & $24 \%$ & $36 \%$ & $20 \%$ \\
\hline \multirow[t]{2}{*}{ 19. Do you think it disrupts our food supply? } & 05 & 07 & 07 & 13 & 13 \\
\hline & $12 \%$ & $15 \%$ & $15 \%$ & $29 \%$ & $29 \%$ \\
\hline \multirow[t]{2}{*}{ 20. Do you think it causes our mangrove deforestation? } & 05 & 05 & 04 & 18 & 12 \\
\hline & $12 \%$ & $12 \%$ & $09 \%$ & $40 \%$ & $27 \%$ \\
\hline \multirow[t]{2}{*}{ 21. Do you think it causes saline intrusion? } & 02 & 10 & 21 & 07 & 05 \\
\hline & $04 \%$ & $22 \%$ & $47 \%$ & $16 \%$ & $11 \%$ \\
\hline 22. Does it causes coastal acquiescent? & 01 & 08 & 09 & 20 & 07 \\
\hline & $2 \%$ & $18 \%$ & $20 \%$ & $44 \%$ & $16 \%$ \\
\hline 23. Do you think it creates problem on fresh water resources? & 01 & 03 & 16 & 13 & 12 \\
\hline & $2 \%$ & $7 \%$ & $36 \%$ & $29 \%$ & $26 \%$ \\
\hline 24. Do you think it causes population displacement? & 01 & 08 & 09 & 20 & 07 \\
\hline & $02 \%$ & $18 \%$ & $20 \%$ & $45 \%$ & $15 \%$ \\
\hline 25. It causes undermining subsistence of local communities. & 01 & 03 & 16 & 13 & 12 \\
\hline
\end{tabular}


26 It causes coastline erosion.

27. It causes salt-water intrusion.

28. It causes fish stocks.

29. It causes inundate low-lying areas.

30. It causes rough weather

31. It causes hot sunshine.

$\begin{array}{lllll}02 \% & 07 \% & 36 \% & 29 \% & 26 \% \\ 02 & 09 & 17 & 14 & 04 \\ 4 \% & 20 \% & 36 \% & 31 \% & 9 \% \\ 01 & 06 & 13 & 21 & 04 \\ 2 \% & 13 \% & 29 \% & 47 \% & 9 \% \\ 02 & 04 & 07 & 19 & 13 \\ 04 \% & 09 \% & 16 \% & 42 \% & 29 \% \\ 04 & 06 & 15 & 13 & 07 \\ 9 \% & 13 \% & 33 \% & 29 \% & 16 \% \\ 02 & 08 & 09 & 22 & 04 \\ 4 \% & 18 \% & 20 \% & 49 \% & 9 \% \\ 01 & 02 & 08 & 24 & 10 \\ 02 \% & 04 \% & 18 \% & 54 \% & 22 \%\end{array}$

Source: Field Study

Appendix-2

One-Sample Test

Test Value $=0$

Sea temperature rises

Sea is acidic

Risk of climate change is to damage property

It damages infrastructure

It damages livelihood

It damages environmental resources

Inundation during storm

Road falls in risk

It causes heat waves

Coastal flood increases

Drought increases

Pollution increases

Precipitation increases

It leads powerful hurricanes

People suffer from allergy

It causes rainstorm

It disrupts food supply

Mangrove deforestation

Saline intrusion

Coastal acquiescent

Scarcity of fresh water

Population displacement

Subsistence of local communities

Coastline erosion

Water intrusion

It reduces fish stocks

Inundate low-lying areas

Rough Weather

Hot sunshine $\begin{array}{ll} & 95 \% \text { Confidence Interval } \\ \text { Sig. (2- Mean } & \text { of the Difference }\end{array}$

T DF tailed) Difference Lower Upper

$\begin{array}{llllll}22.885 & 44 & .000 & 3.53333 & 3.2222 & 3.8445\end{array}$

$\begin{array}{llllll}21.808 & 44 & .000 & 3.31111 & 3.0051 & 3.6171\end{array}$

$16.236 \quad 44 \quad .000$

3.44444

3.0169

3.8720

$22.631 \quad 44 \quad .000$

$17.164 \quad 44 \quad .000$

$3.71111 \quad 3.3806$

4.0416

3.22222

2.8439

3.6006

$20.049 \quad 44 \quad .000$

3.46667

3.1182

3.8152

$\begin{array}{lll}20.935 & 44 \quad .000\end{array}$

3.55556

3.2133

3.8978

$\begin{array}{lll}27.723 & 44 & .000\end{array}$

3.80000

3.5238

4.0762

$\begin{array}{lll}22.611 & 44 \quad .000\end{array}$

3.82222

3.4815

4.1629

$20.569 \quad 44 \quad .000$

3.33333

3.0067

3.6599

$23.125 \quad 44 \quad .000$

3.62222

3.3065

3.9379

$\begin{array}{lll}15.926 & 44 \quad .000\end{array}$

2.80000

2.4457

3.1543

$24.862 \quad 44 \quad .000$

3.88889

3.5736

4.2041

$20.281 \quad 44 \quad .000$

3.44444

3.1022

3.7867

$15.581 \quad 44 \quad .000$

2.66667

2.3217

3.0116

$16.498 \quad 44 \quad .000$

2.91111

2.5555

3.2667

$23.556 \quad 44 \quad .000$

$20.394 \quad 44 \quad .000$

3.55556

3.26667

3.2514

3.8598

$17.119 \quad 44 \quad .000$

$18.812 \quad 44 \quad .000$

$18.766 \quad 44 \quad .000$

$\begin{array}{lll}26.669 & 44 \quad .000\end{array}$

$\begin{array}{lll}21.709 & 44 \quad .000\end{array}$

$18.956 \quad 44 \quad .000$

$\begin{array}{lll}26.317 & 44 \quad .000\end{array}$

$24.556 \quad 44 \quad .000$

$19.406 \quad 44 \quad .000$

$21.305 \quad 44 \quad .000$

$19.239 \quad 44 \quad .000$

3.46667

2.9439

3.5895

3.64444

3.8748

3.13333

3.2540

4.0349

3.73333

2.7968

3.4698

3.55556

3.4512

4.0155

3.26667

3.2255

3.8856

3.51111

2.9194

3.6140

3.75556

3.2422

3.7800

3.31111

3.4473

4.0638

3.73333

2.9672

3.6550

3.24444

3.3802

4.0865

2.9046

3.5843

$29.000 \quad 44 \quad .000$

$3.86667 \quad 3.5980$

4.1354
3.0585 